Check for updates

Cite this: Chem. Sci., 2019, 10, 7952

๑ All publication charges for this article have been paid for by the Royal Society of Chemistry

Received 5th May 2019

Accepted 3rd July 2019

DOI: 10.1039/c9sc02182e

rsc.li/chemical-science

\section{Three-component vicinal-diarylation of alkenes via direct transmetalation of arylboronic acids $\uparrow$}

\author{
Yun Zhang, Gong Chen* and Dongbing Zhao (DD * \\ Herein, we report three-component vicinal-diarylation of non-conjugated alkenes initiated by \\ transmetalation of arylboronic acids, which provides complementary access to $\beta, \gamma$-diaryl carbonyl \\ compounds. We have also screened a large number of chiral ligands for developing an enantioselective \\ version of this reaction and obtained the preliminary results (up to $79: 21$ e.r.). Notably, the methodology \\ developed herein represents the first three component syn-vicinal-dicarbofunctionalization of non- \\ conjugated alkenes involving palladium catalysis.
}

\section{Introduction}

Vicinal-diaryl structures are a common scaffold in various medicinally relevant molecules and can also be widely utilized as chemical feedstocks to access a number of natural products (Scheme 1, upper panel). ${ }^{1}$ Traditional reactions to access vicinal-diaryl structures generally suffer from disadvantages such as multi-step processes, limited substrate scope, and difficulties in accessing starting materials. ${ }^{\mathbf{1 , 2}}$

Alkenes are among the most abundant classes of organic molecules, available in bulk quantities from petrochemical feedstocks and renewable resources. Thus, the intermolecular diarylation of olefins represents one of the most powerful and straightforward methods to rapidly produce vicinal diaryl structures. ${ }^{3}$ For example, homodiarylation of alkenes with aryl metals or halides is a quick method to introduce two identical aryl groups across an olefin. ${ }^{4}$ On the other hand, two general approaches for the introduction of two different aryl moieties across an olefin have been developed: (1) a sequence involving the formation of an Ar-MX species via oxidative addition of an $\mathrm{M}^{0}$ catalyst $\left(\mathrm{Ni}^{0}\right.$ or $\left.\mathrm{Pd}^{0}\right)$ to an aryl electrophile (El), alkene insertion, transmetalation with the aryl nucleophiles $(\mathrm{Nu})$, and $\mathrm{C}-\mathrm{C}$ reductive elimination (Scheme $1 \mathrm{a}$, lower panel); ${ }^{5}$ (2) $\pi$ Lewis acid ( $\mathrm{Pd}^{\mathrm{II}}$ as the Lewis acid) activation of the alkene to enable attack of an aryl $\mathrm{C}-\mathrm{H}$ nucleophile (limited to indoles and phenols) to form a carbopalladated Wacker-type intermediate, followed by the oxidative addition of aryl electrophiles $(\mathrm{Ar}-\mathrm{X}$ ) and $\mathrm{C}-\mathrm{C}$ reductive elimination (Scheme $1 \mathrm{~b}$, lower panel). ${ }^{6}$

State Key Laboratory and Institute of Elemento-Organic Chemistry, College of Chemistry, Nankai University, 94 Weijin Road, Tianjin 300071, China. E-mail: gongchen@nankai.edu.cn; dongbing.chem@nankai.edu.cn

$\dagger$ Electronic supplementary information (ESI) available. CCDC 1852875 and 1852877. For ESI and crystallographic data in CIF or other electronic format see DOI: $10.1039 / \mathrm{c} 9 \mathrm{sc} 02182 \mathrm{e}$
Transmetalation of aryl metal reagents with a palladium(II) catalyst to generate the $\mathrm{Ar}-\mathrm{PdX}$ intermediate has been well documented. ${ }^{7}$ In recent years, several groups have developed an array of methods for alkene functionalization triggered by $\mathrm{Pd}^{\mathrm{II}}$ catalyzed transmetalation of arylboronic acids such as the oxidative boron Heck reaction. ${ }^{\mathbf{8} 9}$ We thus questioned whether three-component heterodiarylation of olefins with aryl halides and arylboronic acids could also be initiated by a transmetalation step (Scheme 1c, lower panel). Such a reaction would provide complementary access to the previous two approaches to vicinal-diaryl structures. Herein, we report the first

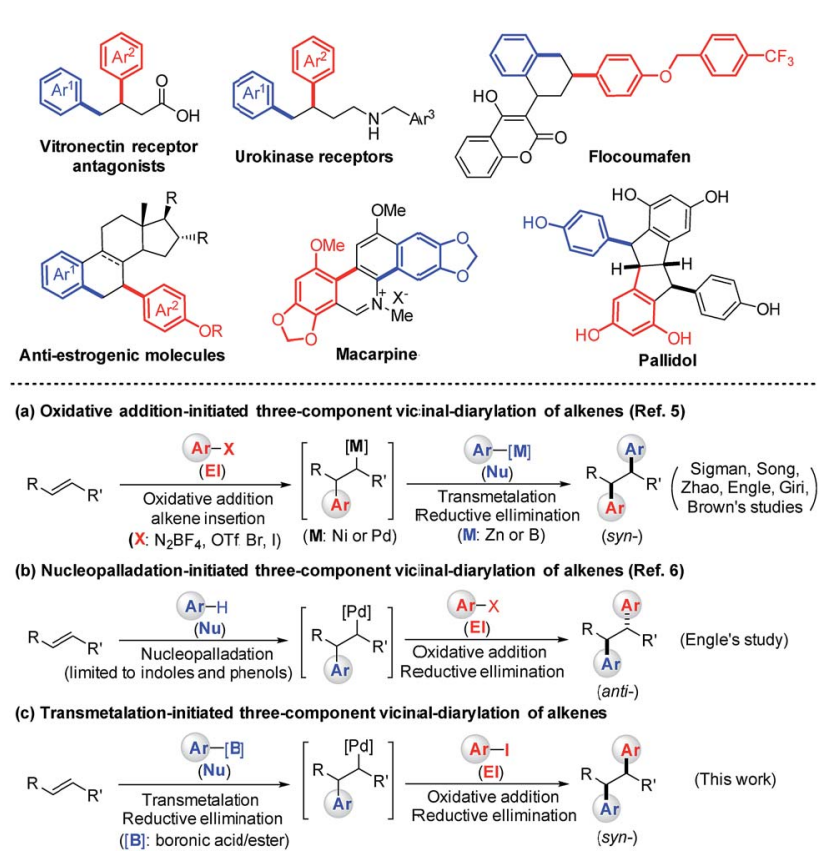

Scheme 1 The usefulness of $\beta, \gamma$-diaryl carbonyl structures as well as the previous work and our design of three-component diarylation of olefins. 
transmetalation-initiated three-component vicinal-diarylation of $\gamma$-olefinic acids by using a directing-group strategy, which enables rapid construction of syn- $\beta, \gamma$-diaryl carbonyl compounds.

\section{Results and discussion}

In a preliminary experiment, a 3-butenoic acid derivative 1a bearing an 8-aminoquinoline (AQ)-directing group ( $0.3 \mathrm{mmol})$ was treated with $\mathrm{Pd}(\mathrm{OAc})_{2}(10 \mathrm{~mol} \%), \mathrm{K}_{2} \mathrm{CO}_{3}(0.3 \mathrm{mmol}), 2$ phenylboronic acid $2 \mathrm{a}(0.6 \mathrm{mmol})$ and 4-methoxyphenyl iodide $3 \mathrm{a}(0.9 \mathrm{mmol})$ in hexafluoroisopropanol (HFIP, $2 \mathrm{~mL})$ at $100{ }^{\circ} \mathrm{C}$ for $24 \mathrm{~h}$, which was completely unreactive (Table 1, entry 1 ). Inspired by Toste's work, ${ }^{10}$ we changed the solvent to a mixture of $\mathrm{DCM} / \mathrm{H}_{2} \mathrm{O} / \mathrm{CH}_{3} \mathrm{CN}(2 \mathrm{~mL}: 0.4 \mathrm{~mL}: 0.2 \mathrm{~mL})$ and the base to $\mathrm{Na}_{2} \mathrm{CO}_{3}(0.3 \mathrm{mmol})$. Then a variety of palladium(II) catalysts were evaluated (Table 1, entries 2-8). (-)-SparteinePdCl 2 was proven to be the best choice (entry 5). Subsequently, different bases were also screened (entries 9-11). All others gave inferior results. We further found that the addition of extra (-)-sparteine $(20 \mathrm{~mol} \%$ ) would increase the yield to $83 \%$ (entry 12 ). The effect of each component of the mixed solvents was also investigated (entries 13-16). It has been proven that all the three solvents are necessary to ensure a satisfactory yield. Switching the solvent back to HFIP dramatically shut off the reaction (entry 17). Notably, we also checked the enantioselectivity of this reaction under the optimized conditions developed in this study. However, the product 4aa was always racemic at this stage. Different types of aryl boron compounds were also screened (entries 18-19).

Having optimized the reaction conditions, we first investigated the substrate scope of aryl boronic acid nucleophiles by using the 3-butenoic acid derivative 1a as the alkene and 4iodoanisole 3a as the electrophile (Scheme 2). To our delight, the reaction was found to tolerate an array of functional groups on the aromatic ring of boronic acid, including electron-neutral, electron-donating and electron-withdrawing substituents, at both the para- and meta-positions (4ba-oa). Substituents on the ortho-position led to a decreased yield, presumably due to steric effects (4pa). Multi-substituted aryl boronic acids (4ra-sa) and heteroaryl boronic acids were also reactive (4ta-ua). It is important to stress that these reaction conditions were compatible with a variety of functional groups such as halogens ( $\mathrm{F}, \mathrm{Cl}$, and $\mathrm{Br}$ ) and acetyl, ester, aldehyde, cyano, and methoxy groups on the aryl boronic acids, which could be subjected to further synthetic transformations.

Subsequently, a variety of substituted aryl and heteroaryl iodide electrophiles were tested under the optimized conditions, and the results are summarized in Scheme 3. It was gratifying to find whether aryl iodides are electron-rich, electron-poor, or sterically hindered, and all of them afforded moderate to high yields (4ac-an). Heteroaryl iodides were also

Table 1 Optimization of the directed three-component syn-vicinal-diarylation of alkene 1a with phenylboronic acids 2a and 4-methoxyphenyl iodide $3 a^{a}$

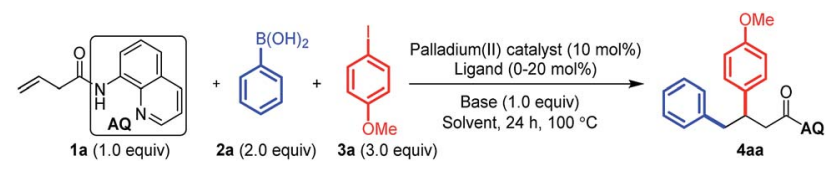

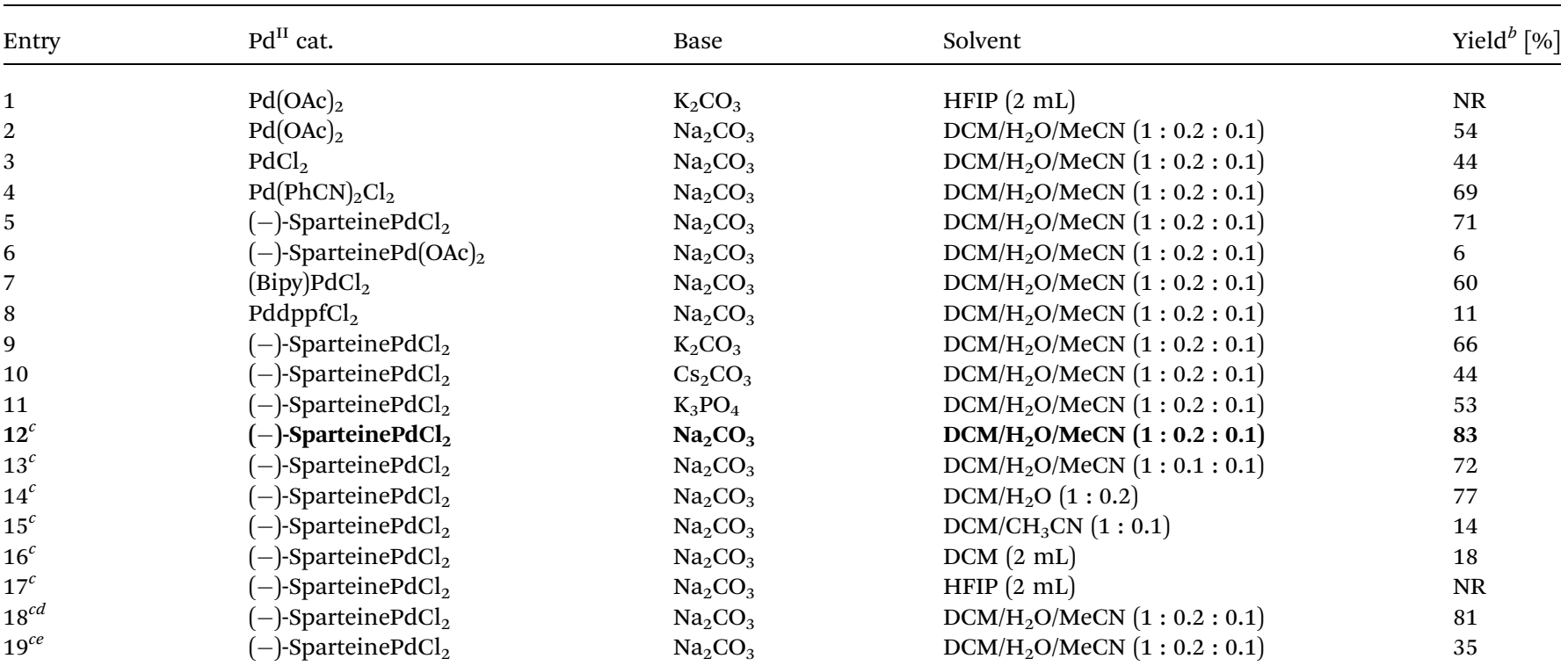

${ }^{a}$ Reactions were carried out by using $\mathrm{Pd}^{\mathrm{II}}$ catalyst (10 mol\%), ligand (0-20 mol\%), base (0.3 mmol, 1.0 equiv.), 1a (0.3 mmol, 1.0 equiv.), phenylboronic acid 2a (2.0 equiv.), and 4-methoxyphenyl iodide $3 \mathrm{a}$ (3.0 equiv.) in the mixture of DCM/ $\mathrm{H}_{2} \mathrm{O} / \mathrm{CH}_{3} \mathrm{CN}(2 \mathrm{~mL}: 0.4 \mathrm{~mL}: 0.2 \mathrm{~mL})$ for $24 \mathrm{~h}$ at $100{ }^{\circ} \mathrm{C}$ under a $\mathrm{N}_{2}$ atmosphere. ${ }^{b}$ Isolated yields. ${ }^{c}(-)$-Sparteine $\left(20\right.$ mol\%) was added. ${ }^{d}(\mathrm{PhBO})_{3}$ instead of $2 \mathrm{a} .{ }^{e} \mathrm{PhBNep}$ instead of $2 \mathrm{a}$. 


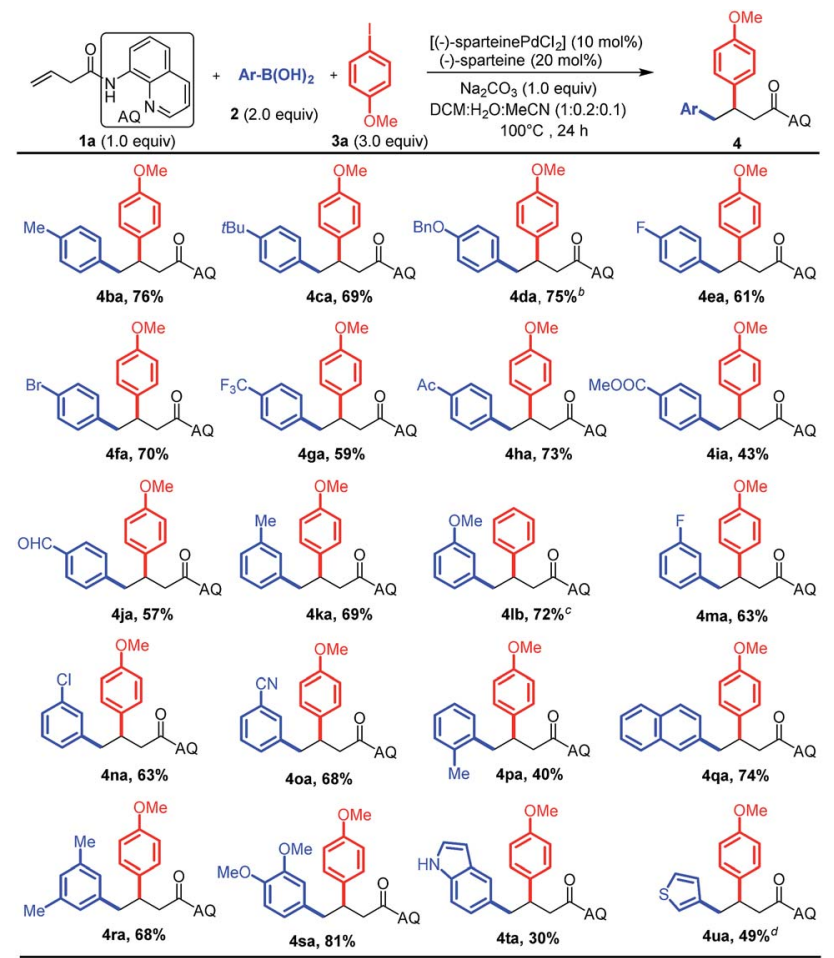

Scheme 2 The substrate scope of aryl boronic acid nucleophiles. ${ }^{2}$ ${ }^{a}$ Reactions were carried out by using (-)-sparteine $\mathrm{PdCl}_{2}(0.03 \mathrm{mmol}$, 10 mol\%), (-)-sparteine (0.06 mmol, 20 mol\%), $\mathrm{Na}_{2} \mathrm{CO}_{3}(0.3 \mathrm{mmol}, 1$ equiv.), 1a (0.3 mmol, 1.0 equiv.), arylboronic acid $2(0.6 \mathrm{mmol}, 2.0$ equiv.), and 4-methoxyphenyl iodide $3 a(0.9 \mathrm{mmol}, 3.0$ equiv.) in the mixture of $\mathrm{DCM} / \mathrm{H}_{2} \mathrm{O} / \mathrm{CH}_{3} \mathrm{CN}(2 \mathrm{~mL}: 0.4 \mathrm{~mL}: 0.2 \mathrm{~mL})$ for $24 \mathrm{~h}$ at $100{ }^{\circ} \mathrm{C}$ under a $\mathrm{N}_{2}$ atmosphere. ${ }^{b}$ Alkene $1 \mathrm{a}(0.2 \mathrm{mmol})$ was used in the reaction. ${ }^{C}$ lodobenzene was used as the electrophile; ${ }^{d}$ the reaction was conducted for $48 \mathrm{~h}$ and 4.0 equiv. of 3a were used.

competent coupling partners (5n). Notably, a lot of important functional groups such as halogens (F, Br, and I), esters, and acetyl groups on the aryl iodides were tolerated, presenting the opportunity for subsequent diversification. Besides diverse (hetero)aryl iodides, the employment of methyl iodide as the electrophile also smoothly delivered the desired products in moderated yields in this reaction (Scheme $3, \mathbf{4 a q}$ ). X-ray analysis of a single crystal $4 \mathbf{a h}$ clearly confirmed that the diaryl groups of the structural connection order in the product is opposite to those vicinal-diaryl products produced by $\mathrm{M}^{0}\left(\mathrm{Ni}^{0}\right.$ or $\left.\mathrm{Pd}^{0}\right)$-catalyzed diarylation of alkenes with aryl electrophiles and nucleophiles. $^{5}$

We next evaluated the utility of this method for various nonconjugated alkenes by using phenylboronic acid $2 \mathbf{a}$ as the nucleophile and 4-methoxyphenyl iodide $\mathbf{3 a}$ as the electrophile (Scheme 4). The terminal alkene bearing mono-substitution at the $\alpha$-position proceeded smoothly to afford the desired product in moderate yield; nevertheless harsher conditions are needed (Scheme 4, 5a). Furthermore, we proved that a variety of internal alkenes could also be efficiently converted into the syn-diastereomers with nearly negligible electronic effects of substituents (Scheme 4, 5b-m). The syn-selectivity of the reaction was confirmed by X-ray analysis of the crystal structure of $5 \mathbf{m},{ }^{11}$

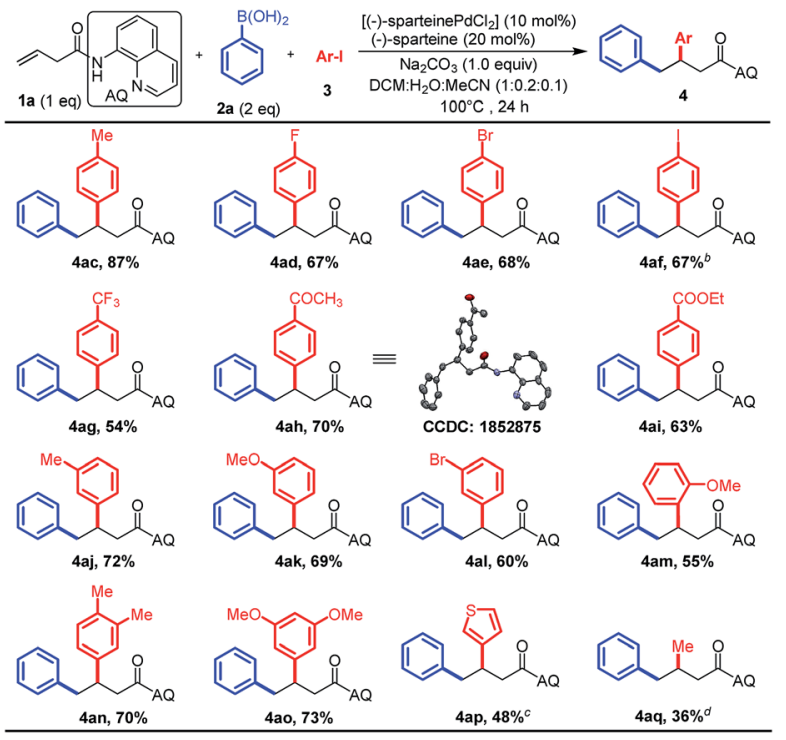

Scheme 3 The scope of aryl iodide electrophiles. ${ }^{a}{ }^{a}$ Reactions were carried out by using (-)-sparteine $\mathrm{PdCl}_{2} \quad(0.03 \mathrm{mmol}, 10 \mathrm{~mol} \%)$, (-)-sparteine ( $0.06 \mathrm{mmol}, 20 \mathrm{~mol} \%), \mathrm{Na}_{2} \mathrm{CO}_{3}$ ( $0.3 \mathrm{mmol}, 1.0$ equiv.), $1 \mathrm{a}$ ( $0.3 \mathrm{mmol}, 1.0$ equiv.), phenylboronic acid $2 \mathrm{a}(0.6 \mathrm{mmol}, 2$ equiv.), and aryl iodide 3 (3-10 equiv.) in the mixture of $\mathrm{DCM} / \mathrm{H}_{2} \mathrm{O} / \mathrm{CH}_{3} \mathrm{CN}$ (2 $\mathrm{mL}: 0.4 \mathrm{~mL}: 0.2 \mathrm{~mL}$ ) for $24 \mathrm{~h}$ at $100{ }^{\circ} \mathrm{C}$ under a $\mathrm{N}_{2}$ atmosphere. ${ }^{b} \mathrm{~A}$ byproduct 4 af' $^{\prime}$ with $8 \%$ yield was observed in this reaction from the activation of the second $\mathrm{C}-\mathrm{I}$ bond in the aromatic ring. ${ }^{\mathrm{C}}$ The reaction was conducted for $36 \mathrm{~h}$ and 4.0 equiv. of aryl iodides were used. ${ }^{d}$ The reaction was conducted for $48 \mathrm{~h}$ and 10.0 equivalent of methyl iodide were used.

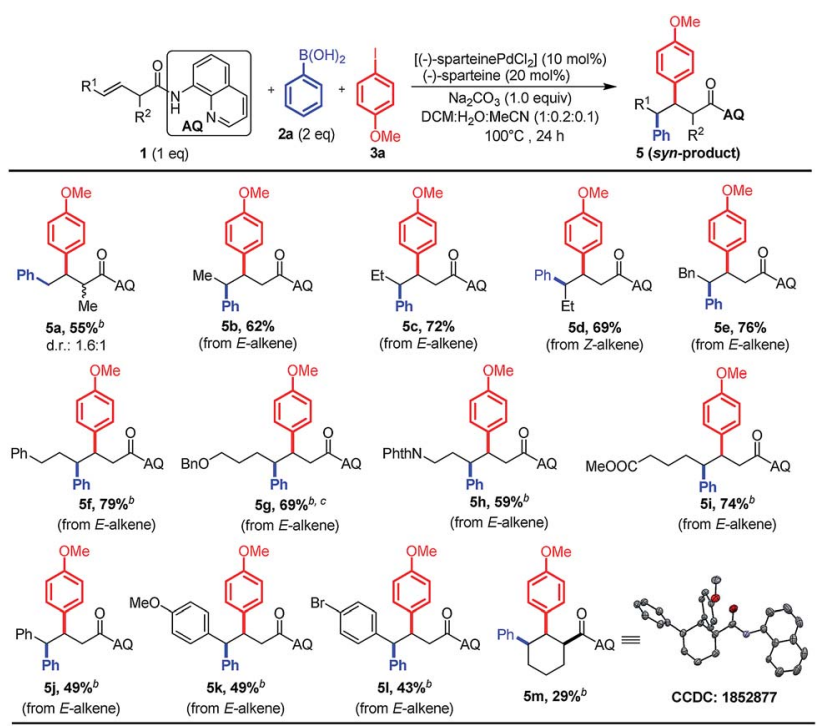

Scheme 4 The scope of various non-conjugated alkenes. ${ }^{\text {a }}$ Reactions were carried out by using (-)-sparteine $\mathrm{PdCl}_{2}(0.03 \mathrm{mmol}, 10 \mathrm{~mol} \%)$, (-)-sparteine ( $0.06 \mathrm{mmol}, 20 \mathrm{~mol} \%), \mathrm{Na}_{2} \mathrm{CO}_{3}$ ( $0.3 \mathrm{mmol}, 1.0$ equiv.), 1 ( $0.3 \mathrm{mmol}, 1.0$ equiv.), phenylboronic acid $2 \mathrm{a}(0.6 \mathrm{mmol}, 2$ equiv.), and 4-methoxyphenyl iodide $3 a(0.9 \mathrm{mmol}, 3$ equiv. $)$ in the mixture of $\mathrm{DCM} / \mathrm{H}_{2} \mathrm{O} / \mathrm{CH}_{3} \mathrm{CN}\left(2 \mathrm{~mL}: 0.4 \mathrm{~mL}: 0.2 \mathrm{~mL}\right.$ ) for $24 \mathrm{~h}$ at $100{ }^{\circ} \mathrm{C}$ under a $\mathrm{N}_{2}$ atmosphere. ${ }^{b}$ The reaction was conducted for $36 \mathrm{~h}$ and 4.0 equiv. of 3 a were used. ${ }^{C}$ An alkene substrate $(0.2 \mathrm{mmol})$ was used in the reaction. 
which was in accordance with our proposed mechanism. Notably, both diastereomers could be accessed based on the stereochemistry of the alkene substrate (i.e., $E$-alkene to $5 \mathbf{c}$ and $Z$-alkene to $\mathbf{5 d}$ ), suggesting that the alkene does not undergo isomerization in the Pd-catalyzed process used in this study. In addition, a pendant phthalimide-protected amine, benzylprotected alcohol and ester were also well tolerated in the reaction $(5 \mathbf{g}-\mathbf{i})$.

In light of our success in the transmetalation-initiated threecomponent vicinal-diarylation of alkenes to synthesize racemic syn- $\beta, \gamma$-diaryl carbonyl compounds, we have tried to develop the enantioselective version of this reaction. After much work on ligand evaluation and optimization of the reaction conditions (see Fig. S2 and S3 in the ESI $\dagger$ for details of the optimization studies), we identified a pyridyl-oxazolidine ligand $\mathbf{L 4 1}$ as an effective ligand, producing a chiral product with moderate enantioselectivity (79: 21 e.r.) and 60\% yield (eqn (1)).

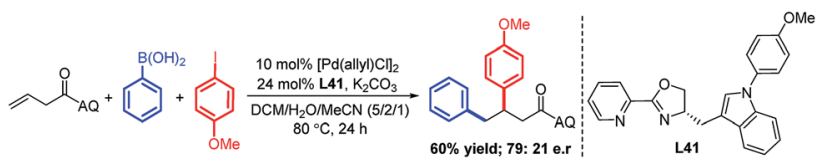

To demonstrate the practicality of this method, we first scaled up the reaction to obtain $\sim 1$ g of 4 aa (Scheme 5 , upper panel). Then, the AQ-directing group was directly removed by treatment with $\mathrm{NaOH}$ to yield the free carboxylic acid 6 via two steps with an overall yield of $81 \%$. Furthermore, the carboxylic acid 8, which has been employed as the intermediate to obtain the natural product pallidol, has been efficiently synthesized with $92 \%$ yield by using the $\operatorname{Pd}($ II)-catalyzed method (Scheme 5, lower panel). In contrast, the methods in the literature involved a non-catalytic procedure with three steps (86\% yield), which shows the advantage and usefulness of our method in the modular synthesis of $\beta, \gamma$-diaryl carbonyl compounds. ${ }^{12}$

On the basis of literature reports, ${ }^{7-9}$ we propose a $\mathrm{Pd}^{\mathrm{II}} / \mathrm{Pd}^{\mathrm{IV}}$ catalytic cycle that starts with the transmetalation (TM) of

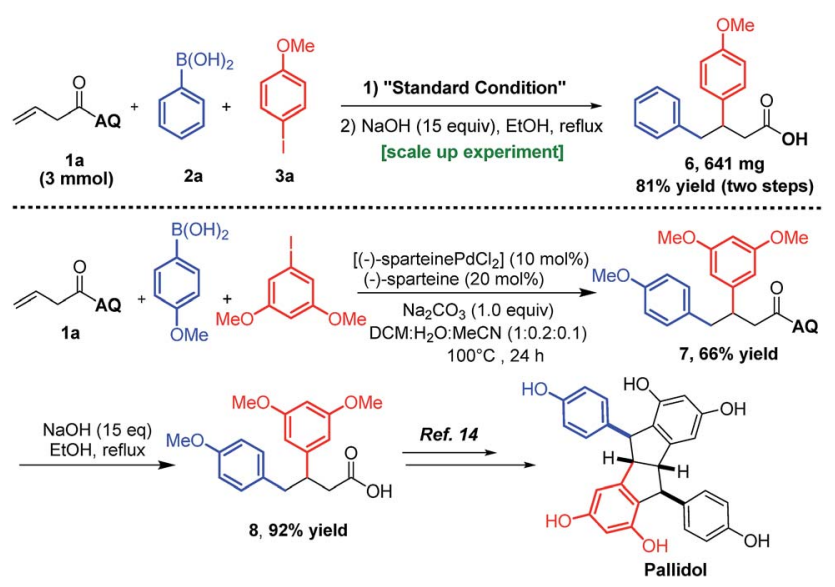

Scheme 5 The synthetic usefulness of our method.

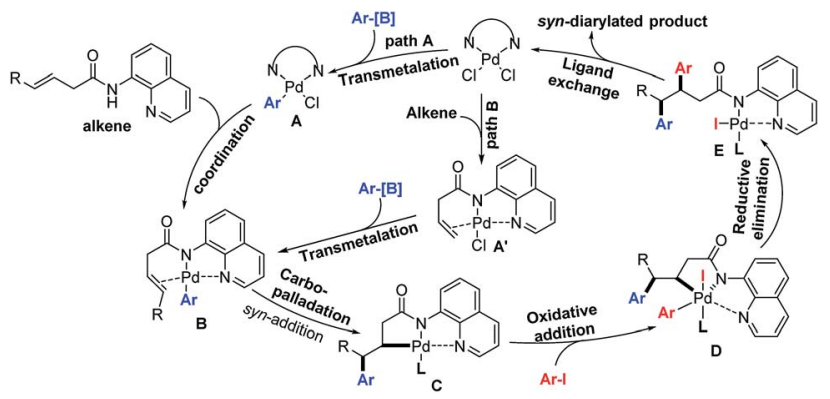

Scheme 6 Proposed catalytic cycle of this three-component vicinaldiarylation of alkenes.

arylboronic acids to form Ar-PdX species A (Scheme 6). Then the Ar-PdX species would coordinate with the directing group and alkene to form the intermediate $\mathbf{B}$, which would involve the carbopalladation step resulting in the intermediate $\mathbf{C}$. Because of the exclusive syn-addition during the carbopalladation step, the stereoselectivity of the as-synthesized diarylated products is opposite to the alkenes produced by the diarylation method involving a Wacker-type anti-nucleopalladation step. ${ }^{6}$ Moreover, the intermediate $\mathbf{C}$ would be intercepted by the oxidative addition of aryl iodides to form $\mathrm{Pd}^{\mathrm{IV}}$ species D. Finally, reductive elimination from the high-valent palladium center and subsequent ligand exchange produce the product and regenerate the $\mathrm{Pd}^{\mathrm{II}}$ catalyst. ${ }^{13}$ Alternatively, alkene coordination with the $\mathrm{Pd}^{\mathrm{II}}$ catalyst could also happen first to form the intermediate $\mathbf{A}^{\prime}$, and then the transmetalation of aryl boronic acids to form the intermediate $\mathbf{B}$.

To support our aforementioned continuous mechanism, several control experiments were performed. We found that no reaction occurred when $\mathrm{N}$-(naphthalenyl)butenamide 9 was used as the alkene substrate (eqn (2)). This result indicates that the presence of the AQ directing group on the unconjugated alkene was indispensable. The Heck reaction between aryl iodides and alkene 1a did not happen under the optimized conditions and $80 \%$ starting material 1a was recovered (eqn (3)). It indicates that the $\mathrm{Pd}^{0}$ species might not be formed in this reaction system. Notably, the homodiarylated product with $8 \%$ yield was observed (eqn (3)). To obtain the intermediate $\mathbf{C}$, the reaction of alkene $\mathbf{1 a}$ and phenylboronic acids $\mathbf{2 a}$ was run in the presence of a stoichiometric amount of the $\mathrm{Pd}^{\mathrm{II}}$ catalyst (eqn (4)). The Heck product $1 \mathbf{k}$ ( $40 \%$ yield) and the starting material 1a ( $51 \%$ recovery) were isolated. It means that the transmetalation of aryl boronic acids and carbopalladation would preferentially occur in the presence of the $\mathrm{Pd}^{\mathrm{II}}$ catalyst, which follows a $\beta-\mathrm{H}$ elimination step in the absence of an electrophile to form the Heck product. To rule out the possibility of the Heck product $\mathbf{1 1}$ as the intermediate for this three-component vicinal-diarylation of alkenes, we carried out the reaction of the Heck product $\mathbf{1 1}$ with aryl iodides with a stoichiometric amount of the $\mathrm{Pd}^{0}$ catalyst (eqn (5)). No desired product 4aa was observed. Finally, we exclude the possibility of the hydrocarbofunctionalized product $\mathbf{1 3}$ as the competent intermediate because only $7 \%$ diarylated product 4 aa was yielded when the 
prepared hydrocarbofunctionalized intermediate $\mathbf{1 3}$ was exposed to the standard conditions in the absence of additional nucleophiles (eqn (6)).
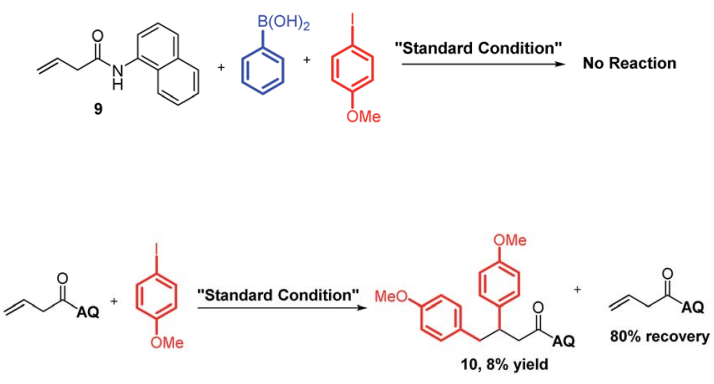

\section{Conclusions}

In conclusion, we have described the transmetalation-initiated three-component syn- $\beta, \gamma$-diarylation of olefins with aryl halides and arylboronic acids. The process is not only simple and convenient in terms of the reaction conditions, but also tolerates a variety of functional groups, thus constituting a practical route to $\beta, \gamma$-diaryl carbonyl compounds prevalent in bioactive molecules.

\section{Conflicts of interest}

There are no conflicts to declare.

\section{Acknowledgements}

We are grateful for the financial support from the National Natural Science Foundation of China (21602115), the 1000Talent Youth Program (020/BF180181), the Natural Science Foundation of Tianjin (18JCYBJC20400), the Fundamental Research Funds for the Central Universities and Nankai University.

\section{Notes and references}

1 (a) I. Ahmad, V. Pathak, P. G. Vasudev, H. K. Maurya and A. Gupta, $R S C$ Adv., 2014, 4, 24619; (b) W. H. Miller, P. J. Manley, R. D. Cousins, K. F. Erhard, D. A. Heerding, C. Kwon, S. T. Ross, J. M. Samanen, D. T. Takata, I. N. Uzinskas, C. C. K. Yuan, R. C. Haltiwanger, C. J. Gress, M. W. Lark, S.-M. Hwang, I. E. James, D. J. Rieman, R. N. Willette, T.-L. Yue, L. M. Azzarano, K. L. Salyers, B. R. Smith, K. W. Ward, K. O. Johanson and W. F. Huffman, Bioorg. Med. Chem. Lett., 2003, 13, 1483; (c) S. Yous, S. Durieux-Poissonnier, E. Lipka-Belloli, H. Guelzim, C. Bochu, V. Audinot, J. A. Boutin, P. Delagrange, C. Bennejean, P. Renard and D. Lesieur, Bioorg. Med. Chem., 2003, 11, 753; (d) T. Watanabe, Y. Ohashi, R. Yoshino, N. Komano, M. Eguchi, S. Maruyama and T. Ishikawa, Org. Biomol. Chem., 2003, 1, 3024; (e) T. Ishikawa, T. Saito and H. Ishii, Tetrahedron, 1995, 51, 8447; $(f)$ S. W. Landvatter and J. A. Katzenellenbogen, J. Med. Chem., 1982, 25, 1300.

2 (a) Z.-M. Chen, M. J. Hilton and M. S. Sigman, J. Am. Chem. Soc., 2016, 138, 11461; (b) E. Larionov, L. Lin, L. Guénée and C. Mazet, J. Am. Chem. Soc., 2014, 136, 16882; (c) C. Zhang and J. Yun, Org. Lett., 2013, 15, 3416; (d) T. Li, J. Zhu, D. Wu, X. Li, S. Wang, H. Li, J. Li and W. Wang, Chem.-Eur. J., 2013, 19, 9147; (e) A. Ziadi and R. Martin, Org. Lett., 2012, 14, 1266; (f) Z. Ding, S. Xue and W. D. Wulff, Chem.-Asian J., 2011, 6, 2130; (g) S. Durieux, A. Chanu, C. Bochu, V. Audinot, S. Coumailleau, J. A. Boutin, P. Delagrange, D. H. Caignard, C. Bennejean, P. Renard, D. Lesieur, P. Berthelot and S. Yous, Bioorg. Med. Chem., 2009, 17, 2963; (h) S. K. Mandal, S. Jana and S. C. Roy, Tetrahedron Lett., 2005, 46, 6115; (i) J. C. Jung, J. H. Lee, S. Oh, J. G. Lee and O. S. Park, Bioorg. Med. Chem. Lett., 2004, 14, 5527; (j) T. P. Blaisdell and J. P. Morken, J. Am. Chem. Soc., 2015, 137, 8712.

3 For some reviews on alkene difunctionalization, see: $(a)$ Y. Ping, Y. Li, J. Zhu and W. Kong, Angew. Chem., Int. Ed., 2019, 58, 1562; (b) R. Giri and S. KC, J. Org. Chem., 2018, 83, 3013; (c) Y. Xiong, Y. Sun and G. Zhang, Tetrahedron Lett., 2018, 59, 347; (d) G. Yin, X. Mu and G. Liu, Acc. Chem. Res., 2016, 49, 2413; (e) E. McNeill and T. Ritter, Acc. Chem. Res., 2015, 48, 2330; (f) R. J. DeLuca, B. J. Stokes and M. S. Sigman, Pure Appl. Chem., 2014, 86, 395; (g) R. I. McDonald, G. Liu and S. S. Stahl, Chem. Rev., 2011, 111, 2981; (h) G. Zeni and R. C. Larock, Chem. Rev., 2006, 106, 4644 .

4 (a) D. Anthony, Q. Lin, J. Baudet and T. Diao, Angew. Chem., Int. Ed., 2019, 58, 3198; (b) A. K. Kusunuru, C. K. Jaladanki, M. B. Tatina, P. V. Bharatam and D. Mukherjee, Org. Lett., 2015, 17, 3742; (c) S. Yahiaoui, A. Fardost, A. Trejos and M. Larhed, J. Org. Chem., 2011, 76, 2433; (d) A. Trejos, A. Fardost, S. Yahiaoui and M. Larhed, Chem. Commun., 2009, 7587; (e) K. B. Urkalan and M. S. Sigman, Angew. Chem., Int. Ed., 2009, 48, 3146. 
5 (a) J. Derosa, R. Kleinmans, V. T. Tran, M. K. Karunananda, S. R. Wisniewski, M. D. Eastgate and K. M. Engle, J. Am. Chem. Soc., 2018, 140, 17878; (b) P. Basnet, S. KC, R. K. Dhungana, B. Shrestha, T. J. Boyle and R. Giri, J. Am. Chem. Soc., 2018, 140, 15586; (c) P. Gao, L.-A. Chen and M. K. Brown, J. Am. Chem. Soc., 2018, 140, 10653; (d) W. Li, J. K. Boon and Y. Zhao, Chem. Sci., 2018, 9, 600; (e) P. Basnet, R. K. Dhungana, S. Thapa, B. Shrestha, S. KC, J. M. Sears and R. Giri, J. Am. Chem. Soc., 2018, 140, 7782; (f) S. Thapa, R. K. Dhungana, R. T. Magar, B. Shrestha, S. Kc and R. Giri, Chem. Sci., 2018, 9, 904; (g) J. Derosa, V. T. Tran, M. N. Boulous, J. S. Chen and K. M. Engle, J. Am. Chem. Soc., 2017, 139, 10657; (h) B. Shrestha, P. Basnet, R. K. Dhungana, S. Kc, S. Thapa, J. M. Sears and R. Giri, J. Am. Chem. Soc., 2017, 139, 10653; (i) Z. Kuang, K. Yang and Q. Song, Org. Chem. Front., 2017, 4, 1224; (j) B. J. Stokes, L. Liao, A. M. de Andrade, Q. Wang and M. S. Sigman, Org. Lett., 2014, 16, 4666.

6 Z. Liu, T. Zeng, K. S. Yang and K. M. Engle, J. Am. Chem. Soc., 2016, 138, 15122.

7 (a) J. Dupont and M. Pfeffer, Palladacycles, Wiley-VCH, Verlag GmbH \& Co. KGaA, 2008; (b) A. de Meijere and F. Diederich, Metal-catalyzed Cross-coupling Reactions, Wiley-VCH, Weinheim, 2nd edn, 2004; (c) J. Tsuji, Palladium Reagents and Catalysts, Wiley, Hoboken, NJ, 2004; (d) E. Negishi and A. de Meijere, Handbook of Organopalladium Chemistry for Organic Synthesis, John Wiley \& Sons, Inc., 2002; (e) J. Tsuji, Transition Metal Reagents and Catalysts, John Wiley \& Sons, Ltd, 2000.

8 For some recent examples, see: (a) L.-J. Xiao, L. Cheng, W.-M. Feng, M.-L. Li, J.-H. Xie and Q.-L. Zhou, Angew. Chem., Int. Ed., 2018, 57, 461; (b) R. Matsuura, T. C. Jankins, D. E. Hill, K. S. Yang, G. M. Gallego, S. Yang,
M. He, F. Wang, R. P. Marsters, I. McAlpine and K. M. Engle, Chem. Sci., 2018, 9, 8363; (c) Q. Yuan and M. S. Sigman, J. Am. Chem. Soc., 2018, 140, 6527; (d) C. Zhang, C. B. Santiago, L. Kou and M. S. Sigman, J. Am. Chem. Soc., 2015, 137, 7290; (e) E. W. Werner and M. S. Sigman, J. Am. Chem. Soc., 2010, 132, 13981; (f) J. H. Delcamp, A. P. Brucks and M. C. White, J. Am. Chem. Soc., 2008, 130, 11270; $(g)$ J. H. Delcamp and M. C. White, J. Am. Chem. Soc., 2006, 128, 15076; (h) A. D. Satterfield, A. Kubota and M. S. Sanford, Org. Lett., 2011, 13, 1076; (i) D. Kalyani, A. D. Satterfield and M. S. Sanford, J. Am. Chem. Soc., 2010, 132, 8419; (j) D. Kalyani and M. S. Sanford, J. Am. Chem. Soc., 2008, 130, 2150.

9 (a) S. KC, P. Basnet, S. Thapa, B. Shrestha and R. Giri, J. Org. Chem., 2018, 83, 2920; (b) S. Thapa, P. Basnet and R. Giri, J. Am. Chem. Soc., 2017, 139, 5700; (c) W. You and M. K. Brown, J. Am. Chem. Soc. , 2015, 137, 14578; (d) H. Cong and G. C. Fu, J. Am. Chem. Soc., 2014, 136, 3788; (e) W. You and M. K. Brown, J. Am. Chem. Soc., 2014, 136, 14730.

10 (a) Y. He, Z. Yang, R. T. Thornbury and F. D. Toste, J. Am. Chem. Soc., 2015, 137, 12207; (b) E. P. Talbot, A. Fernandes Tde, J. M. McKenna and F. D. Toste, J. Am. Chem. Soc., 2014, 136, 4101.

11 CCDC 1852875 (5f) and CCDC 1852877 (6k) contain the supplementary crystallographic data.

12 F. Klotter and A. Studer, Angew. Chem., Int. Ed., 2014, 53, 2473.

13 For reviews on high-valent $\mathrm{Pd}$ in catalysis, see: (a) J. J. Topczewski and M. S. Sanford, Chem. Sci., 2015, 6, 70; (b) A. J. Hickman and M. S. Sanford, Nature, 2012, 484, 177; (c) L. M. Xu, B. J. Li, Z. Yang and Z. J. Shi, Chem. Soc. Rev., 2010, 39, 712; (d) K. Muniz, Angew. Chem., Int. Ed., 2009, 48, 9412; (e) A. J. Canty, Dalton Trans., 2009, 10409. 